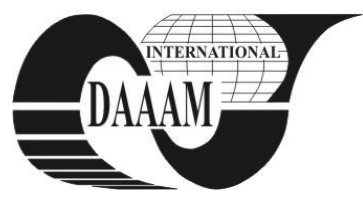

Annals of DAAAM for 2011 \& Proceedings of the 22nd International DAAAM Symposium, Volume 22, No. 1, ISSN 1726-9679 ISBN 978-3-901509-83-4, Editor B. Katalinic, Published by DAAAM International, Vienna, Austria, EU, 2011 Make Harmony between Technology and Nature, and Your Mind will Fly Free as a Bird Annals \& Proceedings of DAAAM International 2011

\title{
DESIGN OF A TRANSMISSION FOR A ELECTRIC POWERED WHEELCHAIR
}

\section{GEONEA, I[onut] D[aniel]; DUMITRU, N[icolae]; UNGUREANU, C[ezar] A[lin] \& CATRINA, G[heorghe]}

\begin{abstract}
In this paper we present a new design variant for an electric powered wheelchair for the persons with locomotor disabilities. The design novelty consist that we use two kinematic chains, one is for the straight line motion, and one for turning. Each kinematic chain is actuated by an electric motor. The turning kinematic chain has in his structure diferential power transmissions.
\end{abstract}

Key words: wheelchair, locomotors disabilities, power transmission, differential mechanism

\section{INTRODUCTION}

Since wheelchairs appeared, only minor changes have occurred with regard to their basic design. An important change was the design of the powered wheelchairs (Dumitru et al., 2010).

Many researchers focused on this area. Literature presents stair-climbing wheelchair mechanism with high single-step capability. The mechanism is based on front and rear wheel clusters connected to the chair via powered linkages, so as to permit both autonomous stair ascent and descent in the forward direction, and high single-step functionality (Lawn, 1997). Some existing scientific papers analyses the characteristics of the topological structures of existing dual-purpose wheelchair mechanisms with dual-functions of sitting and lying (Meng-Hui Hsu, 2009). They are prototype system of a chair equipped with wheels and legs, which is capable of traversing uneven terrain and circumventing obstacles (Wellman, 1995).

All electric power wheelchairs have two motors: one at each wheel, driving one of the main wheels of the chair. Like in the case of wheelchair where the occupant uses the hands to rotate the main wheels on each side, using knobs fixed to wheels, every maneuver is made by varying the relative angular motion of the wheels by each side. From the technical point of view this is called "differential driving".

In the structure of that type of wheelchair are found differential power transmissions. This paper brings arguments for a certain type of drive that achieves the differential movement, on which the traction and the steering components are controlled by separetly motors with suitable synthesis to achieve the proper angular speed difference of wheels, controlled by a control mechanism. In the case of chairs with powered wheels, the differential transmission is realized by proper adjusting of the angular rotation of those two electric motors. Besides the pair of main wheels, the chair has secondary wheels for support. This are straighten automatically in every direction where are pushed.

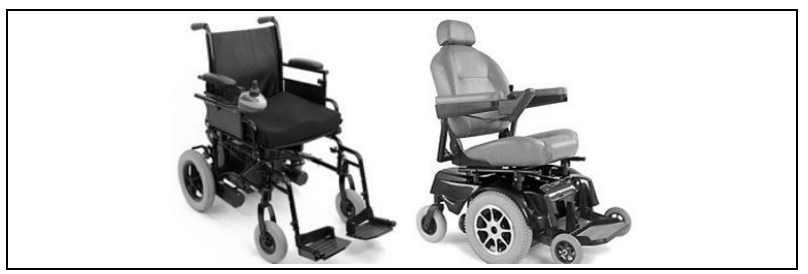

Fig. 1. Electric powered wheelchairs

\section{DESIGN OF THE MECHANISM FOR DRIVING AND STEERING}

The wheel chair has two power chains: one chain assures the straight line motion (traction) and the other power chain assures the steering. The power chain which assure the traction (figure 2), contains the worm 6, the worm gear 5, the final transmission with the wheels 4 şi 2 and 4' şi 2'. The wheels 2 and 2' are fixed to the differential housing 3 and 3'.

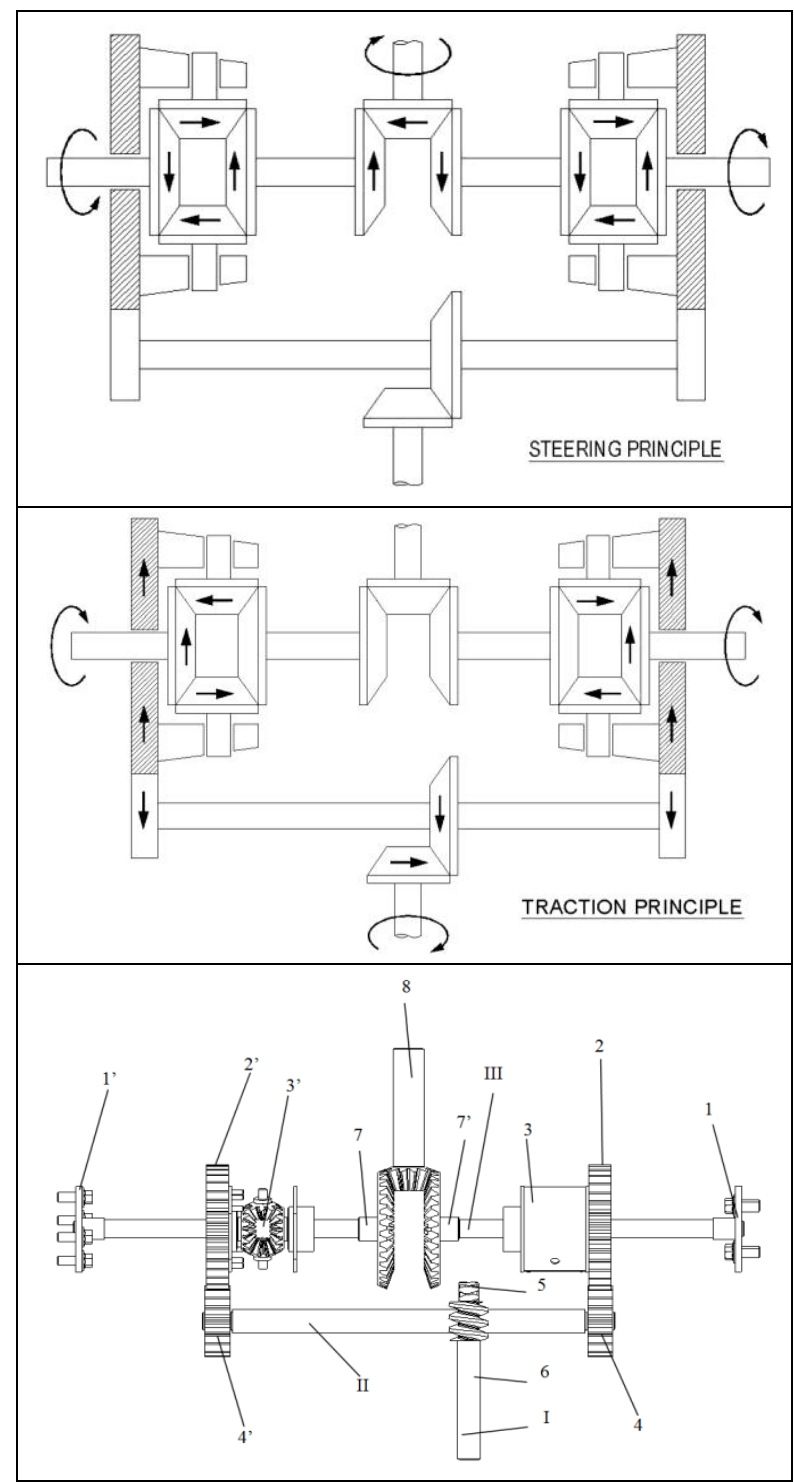

Fig. 2. The wheel chair power chains transmisions

The power chain wich assures the steering consists from the straight bevel pinion 8 and the straight bevel wheels 7 and 7' and the differential mechanisms 3 and 3 '. 
The motion from the actuation motor is transmitted by means of the shaft I to the worm 6, worm gear 5, shaft II and trough the wheels 4 and 4' is transmited to 2 and 2', which are fixed to the differential mechanisms housing 3 and 3 '.

The power chain ratio which assures the straight line driving is calculated with the relation:

$$
i_{t}=i_{m} \cdot i_{f}
$$

where: $i_{m}$ - ratio of the worm gear;

$i_{f}$ - ratio of the final transmision;

The ratio of the steering power transmission is calculated with the relation:

$$
i_{v}=i_{c} \cdot i_{d}
$$

$i_{c}$ - ratio of straight bevel gear;

$i_{d}$ - ratio of diferential power transmision.

The electric motor has the angular speed by $1500 \mathrm{rot} / \mathrm{min}$. The partial gear ratios are: $i_{m}=8, i_{f}=2$, so the shaft II has 187,5 rot/min, and the shaft III has $93 \mathrm{rot} / \mathrm{min}$. The space covered by the wheel is calculated with the relation:

$$
S=2 \cdot \pi \cdot R \cdot n=2 \cdot 3,14 \cdot 0,3 \cdot 4,3=8.1 \mathrm{~m} / \mathrm{s}
$$

The 3D model of the designed power transmission is presented below, in figure 3 .

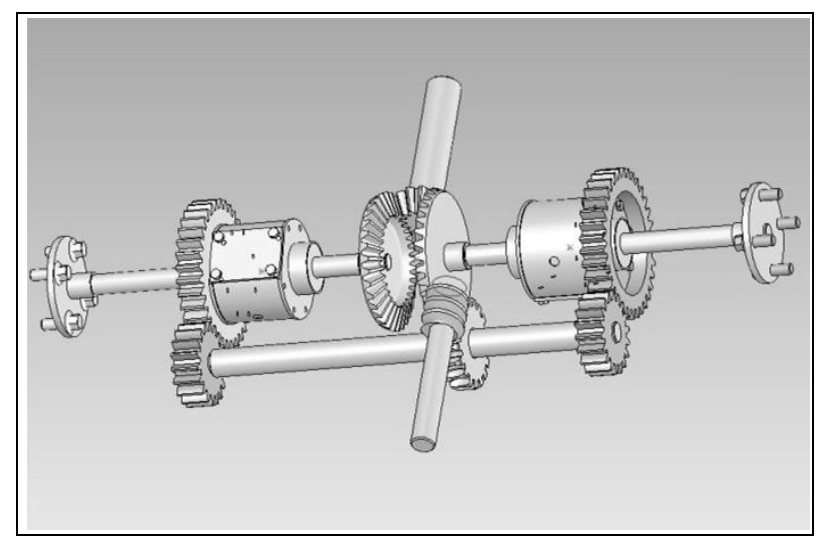

Fig. 3. The 3D model of the power transmision

A section trough the driving power transmission is presented in figure 4.

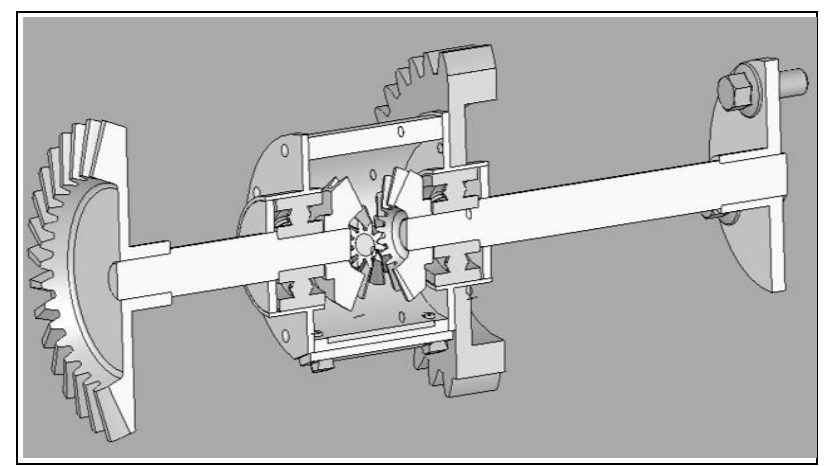

Fig. 4. Section of wheel chair differential transmision

\section{FINTE ELEMENT MODELING OF THE DIFFERENTIAL MECHANISM}

To achieve the finite element modelling we use the finite element program MSC. Visual.Nastran, we follow the stages: - Build of the geometric model of the differential mechanism; - Define of kinematic joints, the motor element variation law, for turning phase, (to one planetary gear, the other being fixed);
- Define of the contact between the gears tooth;

- Finite element meshing;

- Analysis and results processing.

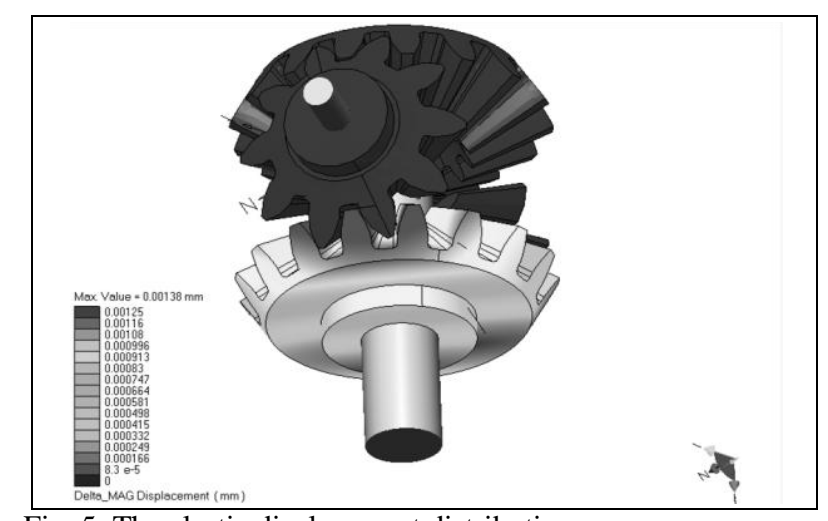

Fig. 5. The elastic displacement distribution

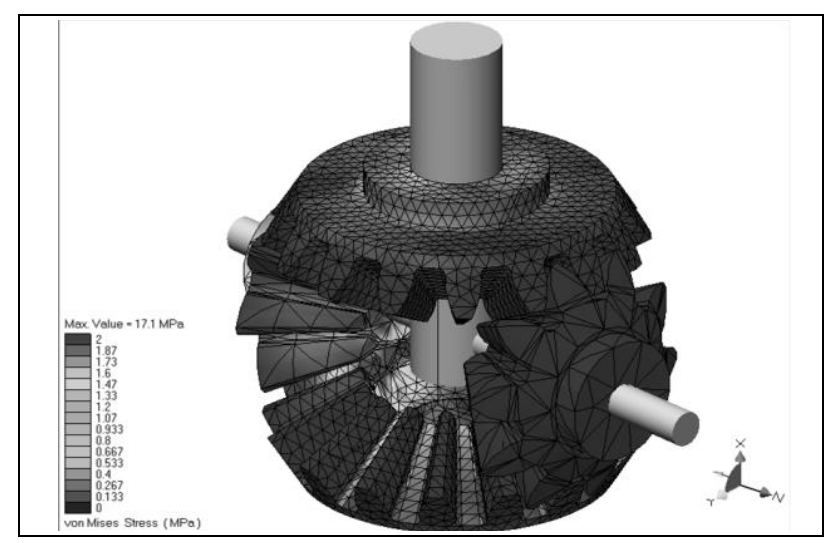

Fig. 6. Von Mises stress distribution

\section{CONCLUSION}

This paper proposes a design modelling of a differentialtype mechanical transmission, in order to ensure the motion of a powered wheelchair, for people with locomotors disabilities. The mechanical transmission is designed to allow the wheelchair displacement for certain posture, namely: displacement in a straight line, displacement on a curve, moving on rough terrain and turning. For the simulations of the transmission functioning in these four cases, the authors propose the virtual prototyping of the constructive solution.

\section{REFERENCES}

Dumitru, N.; Malciu, R. \& Geonea, I. (2010). Differential Transmission for Robotizing a Powered Wheelchair, Proceedings of the OPTIROB, 28-30 May 2010, Published by Research Publishing Services, pp. 47-51, ISBN 978981-08-5840-7, Singapore

Meng-Hui Hsu, Hsueh-Yu Chen. (2009). Dual-Purpose Wheelchair Mechanism Designs, Proceedings of the International MultiConference of Engineers and Computer Scientists 2009 Vol II, IMECS 2009, March 18 - 20, ISBN: 978-988-17012-7-5, Hong Kong

Murray, L. (1997). A robotic hybrid wheelchair for operation in the real world, in Computer Science Center, Nagasaki Institute of Applied Science, No. 8, pp. 65-77, 1997

Murray, L. \& Takakazu, I. (2003). Modelling of a stairclimbing wheelchair mechanism with high single step capability, Available from: http://murraylawn.org/MJLnew W/2003septIEEEtnsreSCW.pdf Accessed: 2011-07-29

Wellman, P; Krovi W. \& Kuma V. (1995). Design of a Wheelchair with Legs for People with Motor Disabilities, in IEEE Trans. Rehab. Eng., vol. 3, pp. 343-353 